\title{
Experimental Investigation on Friction Coefficient between Sawtooth Steel Plate and Concrete
}

\author{
WU Erjun ${ }^{1, a^{*}}$, HU Yuqing ${ }^{1, b}$, ZHANG Nengwei ${ }^{2, c}$, WU Wei ${ }^{1, d}$ \\ ${ }^{1}$ Hohai University, Nanjing 210098, China \\ ${ }^{2}$ Tongji Architectural Design (Group) Co., LTD, Shanghai 200092, China
}

\begin{abstract}
It is easy to think of using sawtooth steel plate on the surface of column to increase the interfacial friction in the temporary RC column underpinning structure. However, there is little research on the friction properties between sawtooth steel plate and concrete. 108 working condition of double interface shear tests were conducted for measuring the friction coefficient between the sawtooth steel plate and the concrete, and the effects of concrete strength, sawtooth size, interface contact method and interface normal pressure on the friction coefficient were also analyzed. The results show that concrete strength on the friction coefficient is not significant when the interface normal pressure is less than $6 \mathrm{MPa}$. After the use of sawtooth steel, the coefficient of friction is greatly improved, and the friction coefficient is approximately linearly related to the aspect ratio of the sawtooth. Damage on the concrete surface will be reduced after adding a flexible material at the contacting interface, but at the same time, it will reduce the friction coefficient. When the sawtooth steel is in direct contact with the concrete, the friction coefficient increases with increasing normal pressure at the interface, however, when the interface is added with flexible material, the friction coefficient is almost irrelevant to the normal pressure.
\end{abstract}

\section{Introduction}

Over the past decades, the renovation of existing buildings is booming in many countries. In the reinforcement and reconstruction projects of reinforced concrete structures, underpinnings technology is widely used[1-3], and the application of temporary underpinning is increasingly widespread. The existing reinforced concrete column underpinning methods, such as Slotted column underpinning[4], Interface anchorage column underpinning[5], Prestressed column underpinning[6], Column underpinning joints with inclined steel bars[7] etc., have the disadvantages of difficulty in being constructed, cut and dismantled, and high cost when applied to temporary underpinning. Despite the technical advantages of easy assembly and disassembly, the having been used steel-type underpinning methods, such as the column-underpinning-node composed of profiled steel and bolt[8], always require several bolts through across the column body, and inevitably part damage of column is produced. Try to develop little damage underpinning methods for RC column, Hohai University[9] proposed a new type underpinning joint for concrete column that load underpinning by friction of sawtooth steel plate and column face. The friction properties of sawtooth steel

\footnotetext{
*corresponding author: ${ }^{\mathrm{a}} 191304020001 @$ hhu.edu.cn

b469684926@qq.com
}

plate and concrete is the basis of the mechanical analysis of this new type underpinning joint.

Since the 1980s, engineers and technicians have conducted a series of studies on the friction properties of steel plate and concrete. In the composite structure, it is generally considered that the force transmitted between the steel and the concrete through the bonding, friction and mechanical occlusion, so as to achieve the cooperative work of the structure[10]. BG Rabbat(1985)[11] studied the friction coefficient of the interface between steel plate and concrete with wet and dry conditions. Peter Baltay(1990)[12] tested the friction coefficient between mild steel and concrete under different interface pressures, The results show that the average coefficient of friction between mild steel and concrete is approximately constant under different interface pressures. Friction coefficient between high-strength concrete(HSC) and rolled steel plate were tested after the concrete specimens exposed to elevated temperatures by XIAO(2012)[13] and the results show that the friction coefficient between HSC and rolled steel plate presents a trend of increasing as the temperature grows. Six groups of specimens with different painting ways were designed and tested to measure the static and dynamic friction coefficient of steel-concrete interface by $\mathrm{SU}(2016)[14]$, and the results of tests show that the painting way of the interface has great effect on the friction coefficient. 
All the above are about the investigation of the friction coefficient between smooth steel plate and concrete. Obviously, the friction coefficient is too small, which limits the application of steel-concrete contacting underpinning method in engineering. Therefore, the author proposed the application of the sawtooth steel plate to contact with concrete, expecting to greatly increase the friction coefficient under the condition that micro-damage occurs on concrete surface. So tests to study the friction coefficient between the sawtooth steel plate and concrete were carried out systematically.

\section{Text Program}

\subsection{Specimen materials and dimensions}

According to GB50010-2010 (Code for design of concrete structure in Chinese), the concrete with strength grades C30, C35 and C40 were adopted. Three cubic test specimens with the size $150 \mathrm{~mm} \times 150 \mathrm{~mm} \times 150 \mathrm{~mm}$ were reserved to test the actual compressive strength for each strength grade and the measured average cube compressive strengths of C30, C35 and C40 specimens are $37.4 \mathrm{MPa}, 38.5 \mathrm{MPa}$ and $43.6 \mathrm{MPa}$ respectively, corresponding cylindrical concrete $(\phi 6$ in $\times 12$ in $)$ strength are 29.5MPa, 30.4MPa, and $34.4 \mathrm{MPa}$.

The size of the sawtooth steel plate is $100 \mathrm{~mm} \times 150 \mathrm{~mm}$ and the thickness is $10 \mathrm{~mm}$ (Figure 1). 4 kinds of sawtooth size were designed and the specific values are shown in Table 1. Smooth surface steel plate $([\mathrm{h}, \mathrm{b}]=[0,0])$ were tested as a control group, where $[\mathrm{h}, \mathrm{b}]=[0,0]$ indicates that the height and width of sawtooth is $0 \mathrm{~mm}$ and $0 \mathrm{~mm}$ respectively, the same below.

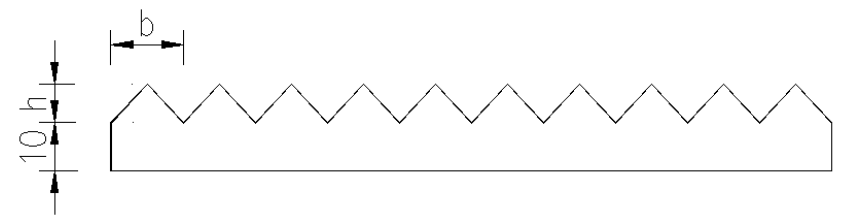

Note: $\mathrm{h}$ and $\mathrm{b}$ in the figure indicate the height and width of the sawtooth, respectively

(a) Sawtooth steel plate schematic

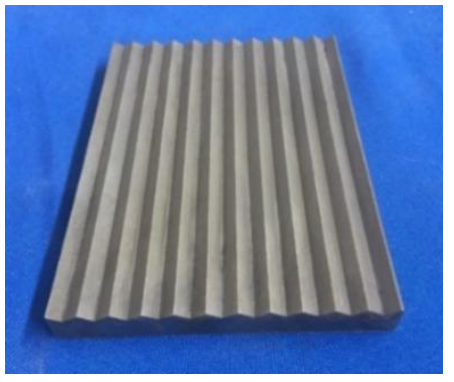

(b) Sawtooth steel plate specimen

Fig.1 Shaping of toothed steel plate

The interface contact method in the steel-concrete friction test including direct contact(C-D), Sandwiching carpet contact(C-C) and sandwiching felt contact(C-F).
The types of felt and carpet are shown in Table 1. The size of felt and carpet are taken as $150 \mathrm{~mm} \times 150 \mathrm{~mm}$ (Figure 2).

Table 1 Interface material parameters

\begin{tabular}{|c|c|c|c|}
\hline Material & Color & Unit weight $\left(\mathrm{g} / \mathrm{cm}^{2}\right)$ & Thickness $(\mathrm{mm})$ \\
\hline Tuffed carpets & Blue & $0.05-0.055$ & $5-8$ \\
\hline Pure chemical fiber felt & Gray & 0.20 & $2-3$ \\
\hline
\end{tabular}

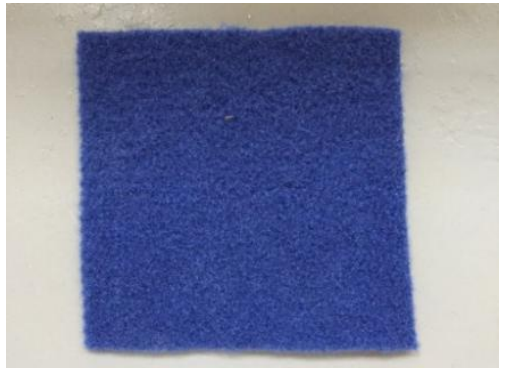

(a) Carpe

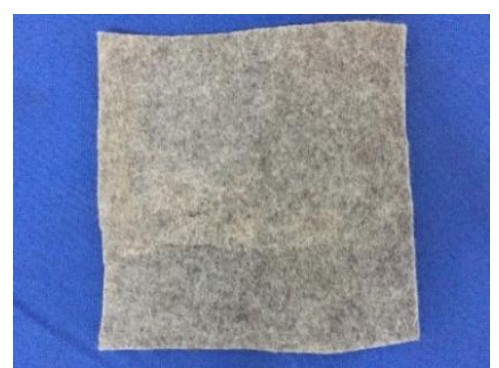

(b) Felt

Fig.2 Interface contact material

pressure on the friction coefficient were considerd. Testing was repeated three times for each working condition, and the average of three test results were taken

\subsection{Test parameter design}

A total of 108 working conditions were designed for this experiment. The effect of concrete strength, sawtooth size, interface contact method and interface normal as the final friction coefficient. The specific parameters are shown in Table 2. 
Table 2 Experimental Investigation Parameter List

\begin{tabular}{|c|c|c|c|c|}
\hline Specimen number & Sawtooth size $[\mathrm{h}, \mathrm{b}]$ & Contact method & Concrete strength grade & Interface normal pressure (kN) \\
\hline 0 & {$[0 \mathrm{~mm}, 0 \mathrm{~mm}]$} & C-D、C-C、C-F & C30、C35、C40 & $30 、 60 、 90$ \\
\hline 1 & {$[3 \mathrm{~mm}, 10 \mathrm{~mm}]$} & C-D、C-C、C-F & C30、C35、C40 & $30 、 60 、 90$ \\
\hline 2 & {$[5 \mathrm{~mm}, 10 \mathrm{~mm}]$} & C-D、C-C、C-F & C30、C35、C40 & $30 、 60 、 90$ \\
\hline 3 & {$[3 \mathrm{~mm}, 5 \mathrm{~mm}]$} & C-D、C-C、C-F & C30、C35、C40 & $30 、 60 、 90$ \\
\hline
\end{tabular}

Note: C-D、C-C、C-F represent Direct contact、Carpet contact、Felt contact respectively

test, a horizontal pressure was loaded on the interface first and then vertical force was load on the top of the

\subsection{Test device}

The tests were carried by double-interface shear method, and the test device is shown in Figure 3. The sawtooth steel plate was placed vertically on both sides of the concrete speceimen, and a pair of steel pads were located at the bottom of the sawtooth steel plate as supports. In a concrete block. The maximum vertical load $\mathrm{F}$ is recorded when the concrete slips, and the friction coefficient $\mu$ between the sawtooth steel plate and the concrete can be obtained by dividing $\mathrm{F} / 2$ by the horizontal normal pressure of the interface.

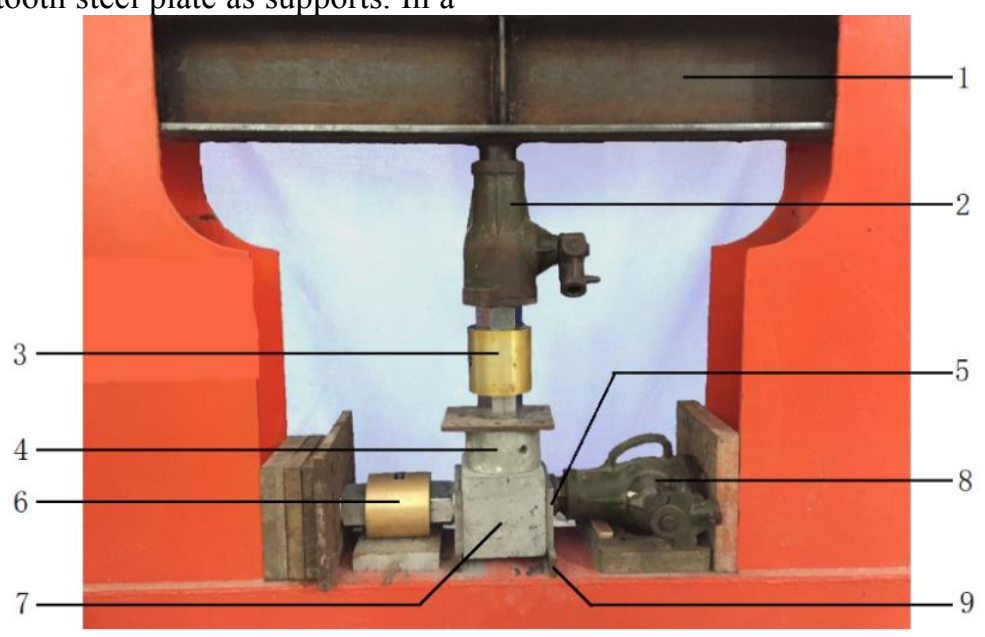

Fig.3 Loading device system

1. Experiment frame; 2. Vertical Jack; 3. Vertical load sensor; 4. Steel pad; 5. Sawtooth steel plate;

6. Horizontal load sensor; 7. Concrete specimen; 8. Horizontal Jack; 9. Steel support pad

\section{Test results}

\subsection{Experimental results and trend analysis of different concrete strengths}

To test the effect of concrete strength on the friction coefficient, using the uniform sawtooth size $([\mathrm{h}, \mathrm{b}]=[3,5])$ and interface contact method (C-D). As a comparison

Table 3 Friction test results for different concrete strengths

\begin{tabular}{|c|c|c|c|c|c|c|}
\hline \multirow{2}{*}{$\begin{array}{l}\text { Sawtooth } \\
\text { size }[\mathrm{h}, \mathrm{b}] / \\
(\mathrm{mm}, \mathrm{mm})\end{array}$} & \multirow{2}{*}{$\begin{array}{c}\text { Concrete strength } \\
\text { (actual strength)/ } \\
\mathrm{MPa}\end{array}$} & \multicolumn{3}{|c|}{$\begin{array}{l}\text { Average friction coefficient } \\
\text { under different interface pressure }\end{array}$} & \multirow[t]{2}{*}{$\begin{array}{l}\text { Average friction } \\
\text { coefficient }\end{array}$} & \multirow[t]{2}{*}{$\begin{array}{c}\text { Standard deviation } \\
\text { /Coefficient of variation }\end{array}$} \\
\hline & & $\begin{array}{r}30 \mathrm{kN} \\
(2 \mathrm{MPa}) \\
\end{array}$ & $\begin{array}{r}60 \mathrm{kN} \\
(4 \mathrm{MPa}) \\
\end{array}$ & $\begin{array}{l}90 \mathrm{kN} \\
(6 \mathrm{MPa}) \\
\end{array}$ & & \\
\hline \multirow{3}{*}[0,0]{} & C30(37.4) & 0.3543 & 0.3400 & 0.3435 & 0.3459 & $0.0257 / 7.42 \%$ \\
\hline & C35(38.5) & 0.3342 & 0.3424 & 0.3559 & 0.3442 & $0.029 / 8.70 \%$ \\
\hline & C40(43.6) & 0.3166 & 0.3420 & 0.3487 & 0.3358 & $0.0213 / 6.33 \%$ \\
\hline \multirow{3}{*}[3,5]{} & $\mathrm{C} 30(37.4)$ & 0.6982 & 0.7136 & 0.7733 & 0.7284 & $0.0428 / 5.87 \%$ \\
\hline & C35(38.5) & 0.7116 & 0.7596 & 0.8259 & 0.7657 & $0.0520 / 6.79 \%$ \\
\hline & $\mathrm{C} 40(43.6)$ & 0.7816 & 0.7570 & 0.8458 & 0.7948 & $0.0500 / 6.30 \%$ \\
\hline
\end{tabular}

group, the friction coefficient test was also conducted with a smooth steel plate. The test results of the friction coefficient of different concrete strengths were shown in Table 3 and Figure 4. 


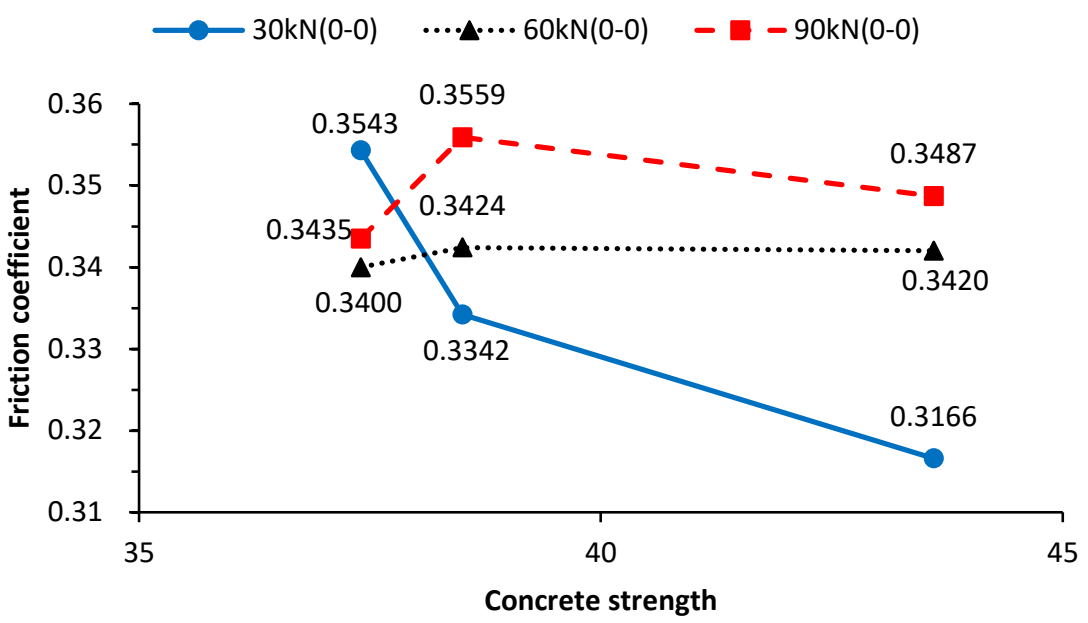

(a) Smooth steel plate $([0,0])$

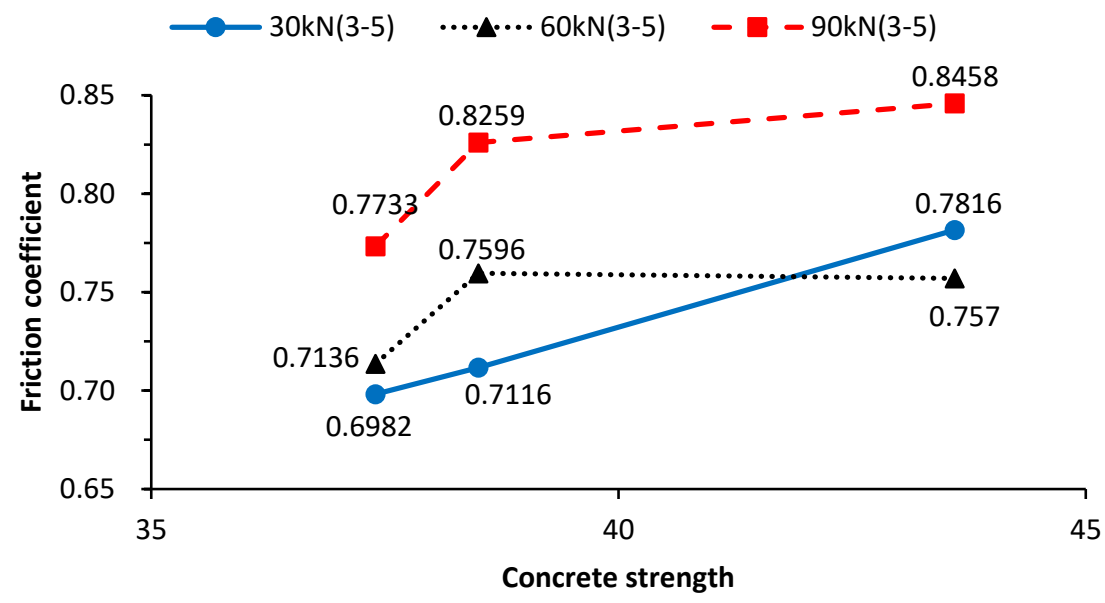

(b) Sawtooth steel plate $([3,5])$

Fig.4 Effect of concrete strength on friction coefficient

From Fig. 4, we can see that the concrete strength has obvious influence on the friction coefficient of steel plate and concrete, but the law under different conditions is not consistent.

For smooth steel plate, the friction coefficient tends to decrease with the concrete strength increases. The reason is that as the concrete strength increases, the compression stiffness of concrete increases, the actual contact area between steel and concrete decrease, and the friction coefficient decreases ${ }^{[14]}$. Under the normal pressure of $2 \mathrm{MPa}$ (Pressure is $30 \mathrm{kN})$, the friction coefficient decreases significantly with the increase of concrete strength. When the strength of concrete ranges from $37.4 \mathrm{MPa}$ to $43.6 \mathrm{MPa}$, the increase is $16.6 \%$, and the friction coefficient decreases $10.6 \%$, However, under the normal pressure of $4 \mathrm{MPa}$ to $6 \mathrm{MPa}$, the change rate of friction coefficient does not exeed $4 \%$.

For sawtooth steel plate, the friction coefficient increases slightly with the concrete strength increases, the maximum increase rate is $11.9 \%$ which occurs under normal stress of $2 \mathrm{MPa}$. The reason is that under the normal pressure of the interface, the steel plate sawtooth are embedded in the concrete surface, the greater the normal pressure is, the deeper the embedding is.. After the vertical shear force is applied, the contact-occlusal-shearing effect occurs at the contact part of the specimen. At this time, the interface bearing capacity is provided not only the friction, but also biting force. As the concrete strength increase, the contact-occlusal-shearing effect is enhanced and the friction coefficient increases. However, when the concrete strength is high, the embedded depth of the steel plate sawtooth decreases. Therefore, the contact-occlusal-shearing effect of the high strength concrete is not significant.

\subsection{Experimental results and trend analysis of different plate sawtooth sizes}

To test the effect of different sawtooth size on the friction coefficient, use the uniform concrete strength C35 (average measured compressive strength $38.5 \mathrm{MPa}$ ) and in condition without the interface material between concrete and sawtooth steel plate. The test results are shown in Table 4 and Figure 5. 
Table 4 Friction test results for different sawtooth size

\begin{tabular}{|c|c|c|c|c|c|c|}
\hline \multirow{2}{*}{$\begin{array}{c}\text { Sawtooth size } \\
{[\mathrm{h}, \mathrm{b}]}\end{array}$} & $\begin{array}{c}\text { Sawtooth aspect ratio } \\
(\mathrm{mm}, \mathrm{mm})\end{array}$ & \multicolumn{3}{|c|}{$\begin{array}{c}\text { Average friction coefficient } \\
\text { under different interface pressure }\end{array}$} & $\begin{array}{c}\text { Average friction } \\
\text { coefficient }\end{array}$ & $\begin{array}{c}\text { Standard deviation } \\
\text { /Coefficient of variation }\end{array}$ \\
\cline { 3 - 6 } & & $\begin{array}{c}30 \mathrm{kN} \\
(2 \mathrm{MPa})\end{array}$ & $\begin{array}{c}60 \mathrm{kN} \\
(4 \mathrm{MPa})\end{array}$ & $\begin{array}{c}90 \mathrm{kN} \\
(6 \mathrm{MPa})\end{array}$ & & \\
\hline$[0,0]$ & 0.0 & 0.3342 & 0.3424 & 0.3559 & 0.3442 & $0.0299 / 8.70 \%$ \\
\hline$[3,10]$ & 0.3 & 0.6412 & 0.5770 & 0.5979 & 0.6054 & $0.0400 / 6.61 \%$ \\
\hline$[5,10]$ & 0.5 & 0.7465 & 0.6523 & 0.7074 & 0.7021 & $0.0510 / 7.26 \%$ \\
\hline$[3,5]$ & 0.6 & 0.7116 & 0.7596 & 0.8259 & 0.7657 & $0.0520 / 6.79 \%$ \\
\hline
\end{tabular}

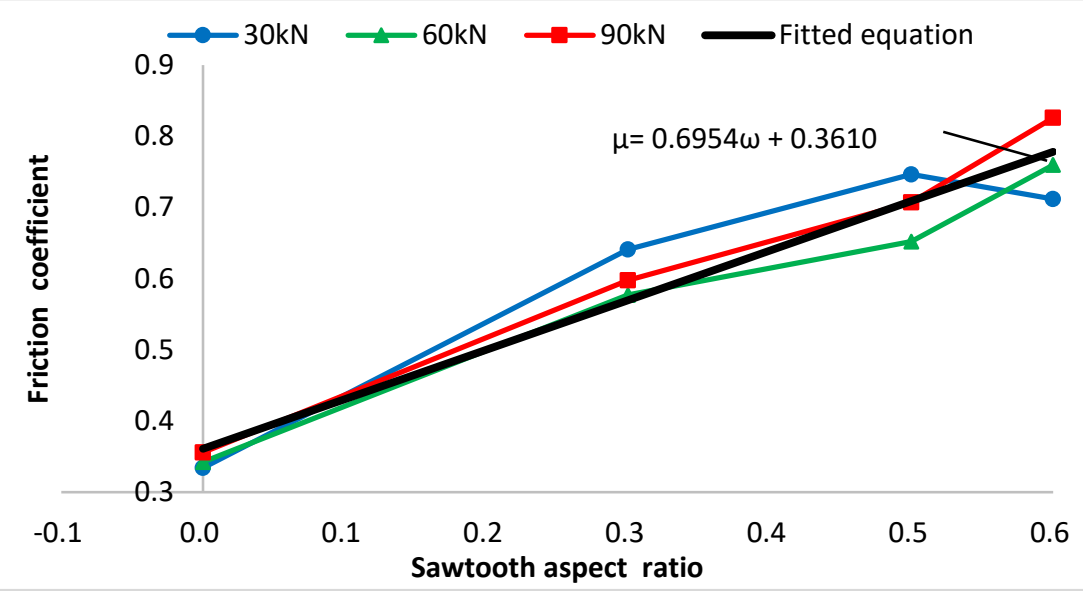

Fig.5 Effect of sawtooth size of steel plate on friction coefficient

From the results of Fig. 5, it can be seen that the sawtooth dimension of the steel plate has significant effect on the friction coefficient between sawtooth steel plate and concrete, and the friction coefficient increases approximately linearly with the increase in the aspect ratio of the sawtooth. The fitted linear equation is also shown in Fig 5. The reason for this phenomenon is that under the normal pressure of the interface, the sawtooth of steel plate are embedded into concrete surface, and resulting in contact-occlusal-shearing-effect. At this point, the measured friction coefficient is actually a nominal friction coefficient. As the aspect ratio of sawtooth increases, the contact-occlusal-shearing-effect is enhanced and friction coefficient increases. We can also find from the test results, the friction coefficient with sawtooth steel plate under the condition of $[\mathrm{h}, \mathrm{b}]=[3,5]$, normal pressure of $6 \mathrm{MPa}$ reaches 2.55 times with smooth steel plate under the normal pressure of 2MPa.

\subsection{Experimental results and trend analysis of different interface contact modes}

To test the effect of interface contact modes on the friction coefficient, use the uniform concrete strength (C35, average measured compressive strength 38.5 $\mathrm{MPa})$ and sawtooth size $([\mathrm{h}, \mathrm{b}]=[3,5])$. The test results are shown in Table 5 and Figure 6.

Table 5 Friction test results of different interface contact forms

\begin{tabular}{|c|c|c|c|c|c|c|}
\hline \multirow{2}{*}{$\begin{array}{c}\text { Sawtooth size } \\
\qquad[\mathrm{h}, \mathrm{b}] \\
(\mathrm{mm}, \mathrm{mm})\end{array}$} & \multirow[t]{2}{*}{$\begin{array}{l}\text { Interface contact } \\
\text { method }\end{array}$} & \multicolumn{3}{|c|}{$\begin{array}{c}\text { Average friction coefficient } \\
\text { under different interface pressure }\end{array}$} & \multirow[t]{2}{*}{$\begin{array}{c}\text { Average friction } \\
\text { coefficient }\end{array}$} & \multirow[t]{2}{*}{$\begin{array}{c}\text { Standard deviation } \\
\text { /Coefficient of variation }\end{array}$} \\
\hline & & $\begin{array}{c}30 \mathrm{kN} \\
(2 \mathrm{MPa}) \\
\end{array}$ & $\begin{array}{r}60 \mathrm{kN} \\
(4 \mathrm{MPa}) \\
\end{array}$ & $\begin{array}{c}90 \mathrm{kN} \\
(6 \mathrm{MPa}) \\
\end{array}$ & & \\
\hline \multirow{3}{*}[0,0]{} & C-D & 0.3342 & 0.3424 & 0.3559 & 0.3442 & $0.0300 / 8.70 \%$ \\
\hline & $\mathrm{C}-\mathrm{C}$ & 0.3858 & 0.3639 & 0.3481 & 0.3659 & $0.0218 / 5.94 \%$ \\
\hline & $\mathrm{C}-\mathrm{F}$ & 0.3807 & 0.3575 & 0.3455 & 0.3612 & $0.0199 / 5.51 \%$ \\
\hline \multirow{3}{*}[3,5]{} & C-D & 0.7116 & 0.7596 & 0.8259 & 0.7657 & $0.0520 / 6.79 \%$ \\
\hline & $\mathrm{C}-\mathrm{C}$ & 0.5779 & 0.5728 & 0.5863 & 0.5790 & $0.0206 / 3.57 \%$ \\
\hline & $\mathrm{C}-\mathrm{F}$ & 0.6740 & 0.6250 & 0.6692 & 0.6561 & $0.0349 / 5.33 \%$ \\
\hline
\end{tabular}




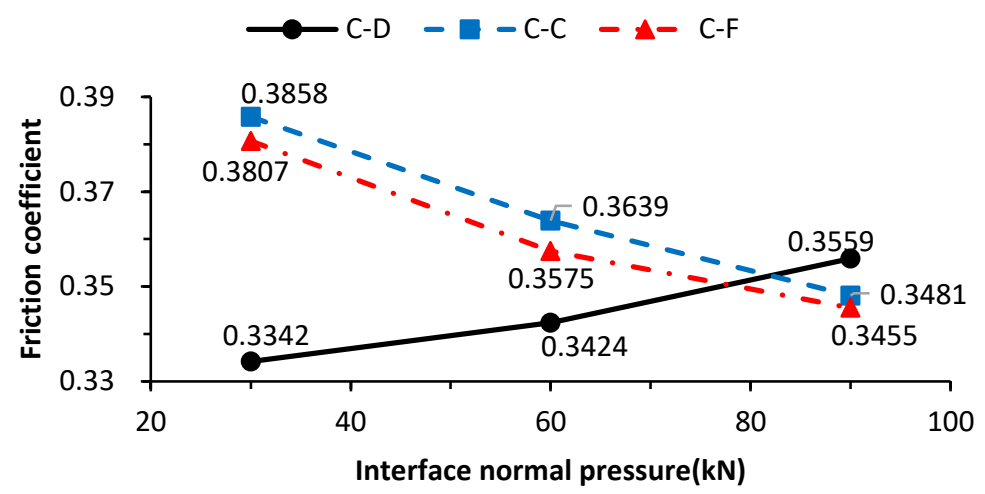

(a) Smooth steel plate $([\mathrm{h}, \mathrm{b}]=[0,0])$

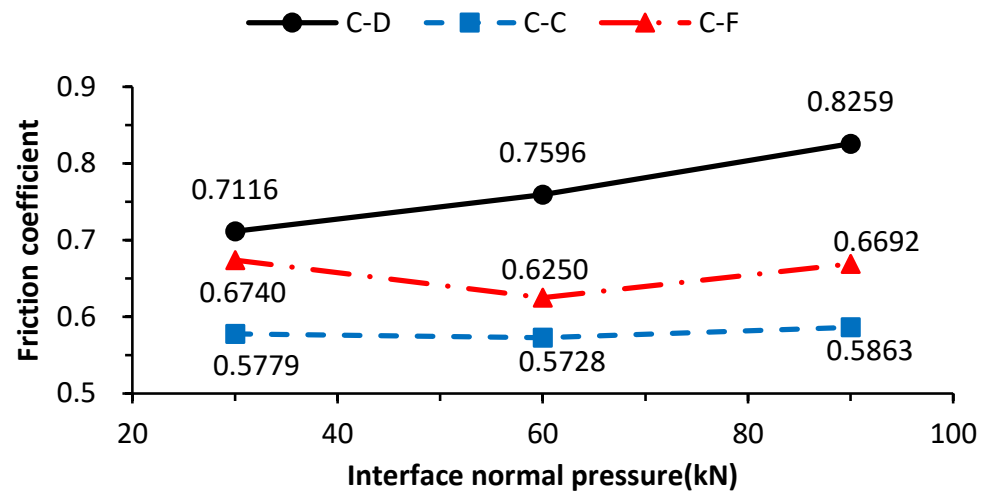

(b) Sawtooth steel plate([3,5])

Fig.6 Interface contact method and interface normal pressure effect on friction coefficient

From Fig.6, it can be seen that for smooth steel plate, adding interface material has slightly influence on the friction coefficient. When adding felt and carpet at the contact interface, the average friction coefficient is $6.3 \%$ and $4.9 \%$ larger than that of direct contact. However the diagram also shows the variation trend of friction coefficient with interface normal pressure increasing is changed. Under the low pressure, adding interface material can increase friction coefficient, whereas under the high pressure, the friction coefficient decrease in the same operation.

For sawtooth steel plate $([\mathrm{h}, \mathrm{b}]=[3,5])$, the friction coefficient between steel plate and concrete is reduced after the interface material is added. When adding felt and carpet at the contact interface, the average friction coefficient was reduced by $24.4 \%$ and $14.3 \%$ compared with the average friction coefficient of direct contact.

\subsection{Experimental results and trend analysis of different interface normal pressure}

From Fig. 6(a), it can be seen that when the smooth steel plate and concrete are in direct contact, the friction coefficient increases slightly with the increasing of the interface normal pressure. After a flexible material added between the sawtooth steel plate and concrete, the events is different. The average friction coefficient reduces by $10 \%$ when interface normal pressure increases from $2 \mathrm{MPa}$ to. $6 \mathrm{MPa}$. It is thought that the additional flexible material under high pressure can compensate for the local micro concave and convex defects on the concrete surface to some extent.

From Fig. 6(b), it can be seen that when the sawtooth steel plate $([\mathrm{h}, \mathrm{b}]=[3,5])$ and concrete are in direct contact, the friction coefficient increases approximately linear with the increasing of the normal pressure at the interface. When the interface normal pressure is $90 \mathrm{kN}$, the average friction coefficient is 0.8259 , which is $16.1 \%$ larger than the average friction coefficient when the interface normal pressure is $30 \mathrm{kN}$. When adding a flexible material between the sawtooth steel plate and concrete, the average friction coefficient under different interface normal pressure is approximately constant.

This phenomenon can be explained as follows: when the sawtooth steel plate and the concrete are in direct contact, as the normal pressure at the interface increases, the contact-occlusion-shearing-effect is enhanced and the friction coefficient measured by the test becomes larger. When adding a flexible material between the sawtooth steel plate and concrete, the contact-occlusion-shearing-effec is weakened due to the barrier effect of the interface material, and the friction coefficient measured in the test decreases and does not change with the normal pressure at the interface.

\subsection{Concrete surface damage}

It is a thing of great concern to engineers to keep the surface of concrete with a slight damage after using the sawtooth steel plate in a temporary underpinning engineering. Figure 7 shows that the surface of the 
concrete is slightly scratched and damaged after sliding between the sawtooth steel plate and concrete contact interface. When different concrete strength, interface normal pressure (average interface pressure 2 6MPa) and interface contact method are used during the test, the degree of damage on the concrete surface is not the same. The specific performance is: when the sawtooth steel plate and concrete are in direct contact, with the increasing of interface normal pressure or the decreasing of concrete strength, the damage of concrete surface becomes more serious; conversely, the damage of concrete surface will be reduced. When the concrete specimen slides, the damage on the top of the concrete surface is more serious than at the bottom. The reason for this phenomenon is: the shear stress on the concrete surface will accumulate after applying vertical shear force, so the shear stress on the top of the concrete surface is larger than the bottom. In another words, there is larger compressive stress in the upper part of concrete block, so greater lateral deformation occurs, and it results in tighter teeth occlusion. In the test, we put a less area cylinder steel pad on the concrete block to try to reduce the effect of inhomogeneous transverse deformation, at the end of the test, corner destruction happened on the top of concrete block, see Fig.7(b).

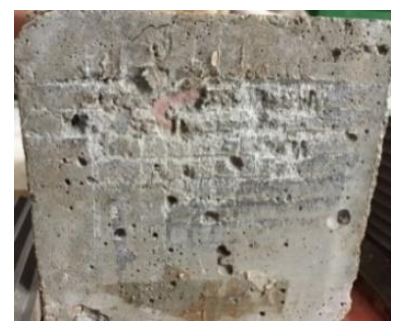

(a) $60 \mathrm{kN}(4 \mathrm{MPa})$

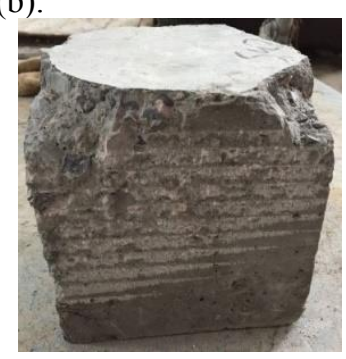

(b) $90 \mathrm{kN}(6 \mathrm{MPa})$
Fig.7 Concrete surface damage

In order to explain the slight damage on the surface of concrete after using the sawtooth steel plate under a certain interface pressure, the numerical simulation analysis is carried out. In the example, the sawtooth height is $5 \mathrm{~mm}$ and the sawtooth width is $10 \mathrm{~mm}$, and the interface normal pressure is $90 \mathrm{kN}$. The Mises stress nephogram calculated by ANSYS is shown in Figure 8 (the stress unit in the figure is MPa). From the Fig.8, it can be clearly seen that there is obvious stress concentration phenomenon between the teeth and the concrete surface, which can make the teeth embedded. As the sawtooth are numerous and dense, the contact pressure is not large and the influence depth is small. Under the condition of underpinned structure with slight damage, the effect of transferring shear force through friction can be greatly improved by controlling the interface pressure and the geometric parameters of the sawtooth. The friction surface is completely unbonded, which greatly improves the convenience of temporary underpinning structure disassembly.

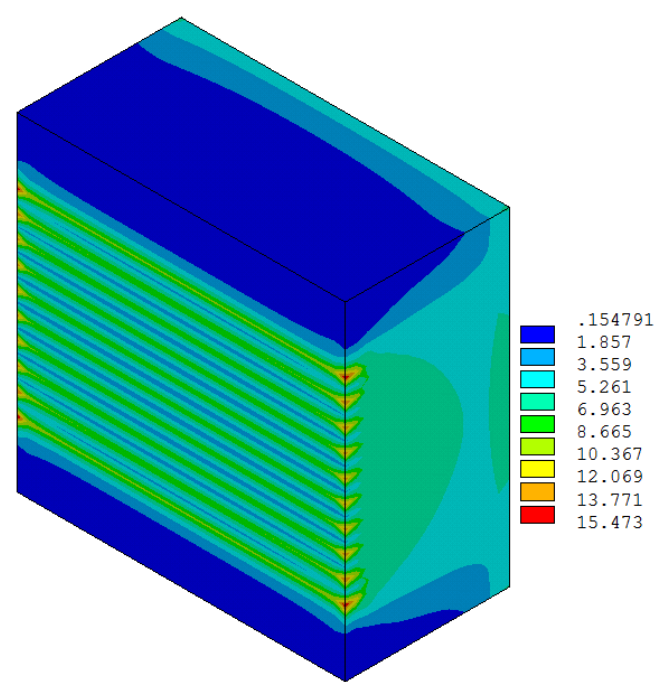

Fig.8 Mises stress nephogram

\section{Conclusion}

Through the analysis of experimental phenomena and data, the following main conclusions can be drawn:

(1) The friction coefficient between the smooth steel plate and the concrete ranges from 0.33 to 0.36 , which is consistent with the experimental results in the literature. The friction coefficient between sawtooth steel plate and concrete ranges from $0.60 \sim 0.83$ under the condition of this paper. The friction coefficient increases significantly with the increase of the aspect ratio of the sawtooth.

(2) For smooth steel plates, the average friction coefficient decreases slightly with concrete strength increasing; For sawtooth steel plate, the average friction coefficient increases slightly with the increase of concrete strength.

(3) The damage of the concrete surface will be reduced after the interface material is added, however, the friction coefficient between steel plate and concrete will also decrease. When adding felt and carpet at the contact interface, the average friction coefficient was reduced by $24.4 \%$ and $14.3 \%$ compared with the average friction coefficient of direct contact.

(4) When the sawtooth steel plate and concrete are in direct contact, the friction coefficient increases approximately linear with the increasing of the normal pressure at the interface. The friction coefficient is almost independent of the normal pressure after adding a interface material.

(5) The variation coefficient of friction coefficient between steel plate and concrete surface is between 3\% and $9 \%$ or so. When the sawtooth steel plate was used, the coefficient of variation of friction coefficient is lower than smooth steel plate was used, and if flexible cushion, such as felt and carpet, are set in the middle of sawtooth plate and concrete, it is slightly lower than that of direct contact.

(6) When the interface normal pressure is less than $4 \mathrm{MPa}$, the sawtooth steel plate will only cause micro-damage to the concrete surface. 


\section{Acknowledgements}

The authors would like to thank NSFC for their financial support (Project No. 51978242), and thank Miss Jinlin $\mathrm{Hu}$ of the Structure Laboratory, Hohai University for her help in the experiment processes.

\section{References}

1. Pryke J F S. ,1982.Underpinning, Framing, Jacking-up and Moving Brick and Stone Masonry Structures. In: Proc. ICE Conf. London.

2. Pryke J F S., 1983.Relevelling, Raising and Resisting Historic buildings. In: Proc. Symp IABSE. London.

3. Wu E J, Li A Q, Zhang X L. (2011) Development and Prediction of Building Monolithic Moving Technology. Construction Technology,40(337):1-7.

4. Wu E J. Research on key technolocy and application of building monolithic moving engineering[D]. Nanjing: Southeast university,2003. (In Chinese)

5. Cao Z N. Study on behavior of reinforced concrete column prestressed underpinning joint[D]. Nanjing: Hohai university,2013. (In Chinese)

6. Yue Q X, Zhang X, Jiang Z R. (2016) Experimental study on mechanical properties of pre-stressed underpinning jionts. Journal of Buliding Structures, 37(8):58-65.

7. Wu E, Dong N, Yuan K. (2017) Experimental study on column underpinning joints with inclined steel bars. Structures \& Buildings, 170(10):751-764.

8. Wu E J, Li A Q, Guo T. (2003) Experimental study on shear behavior of column-underpinning-node composed of profiled bar and bolt. Journal of southeast university (Natural Science Edition), 33(5):631-634.

9. Wu E J, Zhang N W. A detachable profile-steel underpinning device for $\mathrm{RC}$ column and its application method. [P]. Chinese Patent: 201710093223.0, 2017.02.01.

10. Chen Z P, Liang Y, Chen Y L. (2014) Research on bonding strength of steel and concrete with different bonding interfaces. Applied Mechanics and Materials, 470:838-841.

11. Rabbat BG, Russell HG. (1985) Friction coefficient of steel on concrete or grout. Journal of Structure Engineering, 111(3):505-515.

12. Baltay P, Gjelsvik A. (1990) Coefficient of friction for steel on concrete at high normal stress. Journal of Materials in Civil Engineering, 2(1):46-49.

13. Xiao J Z, Zhao W P. (2012) Shear bond strength and friction coefficient between high-strength concrete and rolled steel plate after elevated temperatures exposure. Journal of building materials, 15(5):697-702.

14. Su Q T, Du X, Li C X. (2016) Tests of basic physical parameters of steel-concrete interface.
Journal of TongJi university(natural science), 44(4):499-506.

15. China Architecture \& Building Press. Code for design of concrete structure.2011.

16. Standards Press of China. Industrial felt. 2012.

17. Standards Press of China. Tuffed carpets. 2009. 